\title{
An Examination of Time-Use and Transportation Barriers to 2 On-Campus Participation of University Students
}

\author{
3 Jeff Allen \& Steven Farber \\ 4 SAUSy Lab \\ 5 Department of Geography and Planning \\ 6 University of Toronto St. George \\ 7 Contact: jeff.allen@mail.utoronto.ca
}

\begin{abstract}
8 Abstract
9 Success in postsecondary education is related to the amount of time spent on cam10 pus. The more often students attend class and access on-campus learning resources, 11 the better their grades and the lower their dropout rates. Despite the importance of 12 on-campus participation in student outcomes, some students living in large cities face 13 tremendous transportation and time-use barriers that make it difficult to spend more 14 time on campus. Accordingly, the objective of our project is to examine the mobility 15 factors that prevent students from attending their campuses in the Greater Toronto 16 Area (GTA). Specifically, we examine student disparities in barriers to participate 17 based on where they live, their mobility options, as well as the time constraints of 18 their daily activity patterns (e.g. part time work). Data for our project is drawn 19 from a 1-day travel survey of students across seven university campuses in the GTA. 20 This is augmented with computationally derived transport accessibility factors. Mul21 tivariate logistic regression models are then employed to uncover the mobility-related 22 determinants for a) if students feel commuting discourages them from travelling to 23 campus; b) if students pick courses based on their commute; c) if commuting discour24 ages students from participating in university organized activities; and d) how many 25 days per week a student visits campus. The results of these models fuel a discussion 26 of how to limit mobility-related barriers to postsecondary student participation.
\end{abstract}

\section{Keywords}

28 university students, commuting, time use, activity participation, logistic regression 


\section{Introduction}

2 Time is a finite resource. The more time postsecondary students spend commuting or partaking in employment, the less time they have to attend class or study, limiting their academic potential (Tinto, 1993, 1999). Research on the deterrents of on-campus participation have focused on time-use factors like employment or taking care of family (Reay, Ball, \& David, 2002; Bozick, 2007). Yet in large metropolitan areas, transportation related factors, like limitations in accessibility and mobility, can be a barrier to activity participation (McCray \& Brais, 2007; Lucas, 2012). Accordingly, the objective of this paper is to uncover how both time-use and transportation related factors potentially limit students from travelling to campus, accessing oncampus educational resources, and participating in on-campus activities. Data is drawn from a 2015 travel survey of students across seven University campuses in the Greater Toronto Area (StudentMoveTO, 2015) and additional transport accessibility and transit level-of-service variables were derived via custom-built multi-modal network graphs. From the survey, the majority of students indicate that their commutes discourages them from travelling to campus and participating in on-campus organized activities. Multivariate logistic regression models are employed to examine the factors affecting weekly commute frequency as well as the probability of a student responding yes or no to a series of questions of whether commutes discourage on-campus participation. Findings show that after controlling for socio-demographic and educational factors, durations of home-campus trips and employment hours per week have significant negative effect on how often students travel to and participate in activities on campus. This leads to policy recommendations directed at reducing these transportation barriers, including better scheduling of transit service at campuses, more affordable transit fares, encouraging active modes of transport, and decreasing the costs of on-campus housing.

The paper is outlined as follows: the first section provides background on how on-campus participation affects student outcomes, postsecondary student travel behaviour, and how transportation can be a barrier to activity participation; the second section outlines the data and study area; the third section provides description of the methodology and outputs of the analysis; and the fourth is a discussion of results with focus on how to limit mobility-related barriers to postsecondary student participation.

\section{${ }_{34} 2$ Background}

35 On-campus participation has been shown to be correlated with better grades and 36 fewer drop-out rates (Tinto, 1993). The more time students are at campus, the more 37 time they have to attend class, visit libraries, and access other on-campus educa- 
1 tional resources. Furthermore, attending campus increases opportunity for building peer-networks, interacting with professors and other academic staff, and engaging in extra-curricular activities. These on-campus social activities can enrich learning and increase potential opportunities when entering the job market (Tinto, 1999). From a zero-sum perspective, time spent on campus can be limited by time spent doing other activities. The more time students spend at other non-campus oriented activities, the less time students have to attend class, study, and access on-campus learning resources (Bozick, 2007).

Research on the deterrents of on-campus participation have focused on how time spent in activities like employment or taking care of family limit time spent on-campus. Postsecondary students typically do not have the qualifications for wellpaying employment, and are usually in lower-income brackets. Many students need to partake in relatively low paying part-time work to fund their education. The increased time spent working limits the time directed towards education. In one study, Bozick (2007) analyzed a dataset of ten thousand first-year students across multiple postsecondary institutions in the United States and found that a lack of economic resources for some students results in them having to partake in more employment, limiting the time they can study and attend class, and increased the likelihood to drop out of school. In another study, Dwyer, Hodson, and McCloud (2013) used a longitudinal survey of youth in the United States and found that those who have compounded debt from tuition payments, and need to take employment to relieve their debt, have a greater risk of dropping out. Other research has examined the barriers to educational participation for students with greater household responsibilities. For example, Reay et al. (2002) conducted detailed interviews of mature students in London, U.K. and found that students who have increased household responsibilities, and in particular have dependent children, are more prone to dropping out of school because they have less time to focus on education. This is often compounded with the necessity of part-time employment to pay for education as well as the cost of living for more than one person (Reay et al., 2002).

Continuing from a zero-sum perspective, the time spent commuting could also limit participating in on-campus activities. Post-secondary students face their own specific transport related barriers that are different from other groups. University campuses are only located at certain locations and students thus have limited locational choice of where to go to school, and because of economic restrictions, many are limited in terms of their choice of housing as well as the mobility options available to them (Abercrombie, 1974; Bozick, 2007; Kamruzzaman et al., 2011). This can result in long commutes reducing time spent on-campus. This problem is potentially compounded for universities in large metro areas, since home-campus commutes can be longer, more expensive, and more stressful than universities in smaller towns. Moreover, schedules of postsecondary students are more flexible than high school students or traditional fixed-location employees. Postsecondary students have less mandatory 
1 in-class time, some freedom to select and structure their own timetables, and they

2 can choose how much time to spend on campus and participate in extra-curricular activities, educational or social. On the one hand, this flexibility may provide students with the ability to juggle multiple demands on their time, precarious access to mobility tools, or long commutes, to enable participation in on-campus activities. On the other hand, we hypothesize that if students have poor access to their campuses, increased flexibility could potentially discourage students to visit campus as participation is not usually mandatory, causing them to miss class, not access other optional on-campus educational resources, and limit them in building social networks.

In recent years, there has been an increase in transportation research focusing on the linkages between (in)accessibility, activity participation, and social exclusion (McCray \& Brais, 2007; Lucas, 2012). Transport-related accessibility refers to the capability of a city to provide opportunities for interaction, including the exchange of information, goods, labour, and services. This includes access to postsecondary education. Accessibility varies by a number of factors like land use patterns, travel mode, time of day, and socioeconomic status (e.g. can someone afford to travel). From a time geography approach, a person's path and participation in activities throughout a day is structured by having to be at certain places at certain times, while potential movement and activity in the intermediary periods is limited to varying extents depending on available transport networks (Hägerstraand, 1970). Ample research has shown that activity participation can be constrained by social, spatial, and temporal accessibility restrictions (Cullen \& Godson, 1975; Hanson, 1982; Miller, 1991). The inaccessibility inequalities of transport networks limit the opportunities available to people, deters participation, and can even foster social exclusion (McCray \& Brais, 2007; Grengs, 2015). The social outcomes of transportation planning has increasingly become a pertinent objective for transport policy officials and researchers (Lucas, 2012; Martens, 2016). Certainly, completely equitable access is unattainable since space is never uniform in terms of its relative distance to location based opportunities. But good transportation policy, and good urban form more generally, should attempt to minimize accessibility inequalities, particularly if they exist along socioeconomic cleavages (Lynch, 1981; McCray \& Brais, 2007).

Measuring access in urban systems is complicated by multiple travel modes, activity types, time constraints, and mobility options (Cullen \& Godson, 1975). Accessibility is often analyzed using geographic information systems, and in particular, network analysis (Miller, 1999). These technologies can also be extended temporally to map and analyze urban accessibility to incorporate the inherent temporal variations in accessibility within transit schedules (Lei \& Church, 2010). Increased capabilities in computation in recent years have facilitated minute-by-minute analysis of the temporal variations inherent in transit schedules, which can be used to compute measurements of average accessibility over certain time periods, like a morning commute (Owen \& Levinson, 2015; Farber \& Fu, 2017). This can also be extended 
1 to look at the attributes of a trip. For some people, transit trips can seem less desir2 able if they include multiple transfers or longer walking distances, even if the overall 3 journey time is the same (Kittelson \& Associates, 2003).

There have been several projects which have examined the travel behaviour of university students specifically. Many have focused on examining their mode choice behaviour (Shannon et al., 2006; Delmelle \& Delmelle, 2012; Lundberg \& Weber, 2014; Moniruzzaman \& Farber, 2017), but less have focused on analyzing students' activity participation rates. An early approach was conducted by Abercrombie (1974), who examined the daily activity patterns of students in London, UK. Their analysis consisted of categorizing activities (e.g. school, work, shopping, leisure) and then examined how participation in these activities varied over the course of a day and for different demographic groups (Abercrombie, 1974). More recent studies have examined how distance to campus limits scholastic participation. For example, Frenette (2004, 2006) analyzed how proximity to Universities in Canada limits initial enrolment, particularly for students from lower income families, primarily because of the costs associated with having to relocate. Other studies have focused on the dayto-day aspects of travel behaviour and activity participation of students. Using the same data as our study, Habib (2017) modelled the factors of how many days per week students study from home (i.e. tele-commuting). They found that distance from campus had a positive effect in terms of tele-commute frequency, but this study did not consider the effects of time-use constraint variables such as employment. In a 2010 study of commute satisfaction postsecondary students in Hamilton, Ontario, Páez and Whalen (2010) found that active travellers are generally less dissatisfied with the durations of their commutes compared to car and transit users. In a study of students in Northern Ireland, Kamruzzaman et al. (2011) used a 2-day travel diary to examine postsecondary student activity spaces by distance travelled, travel time, and daily activity duration. They found that less accessible areas resulted in fewer trip rates to various activities, including education, and then used this analysis to recommended new transit routes to serve these less accessible areas. In a similar study, Wang, Khattak, and Son (2012) utilized a survey in Norfolk, Virginia to model trip frequencies of students and found that students who live closer to campus take more trips, visit more destinations, and utilize more active modes, than students living further away. The studies by Wang et al. (2012) and Kamruzzaman et al. (2011) focused on the summation all trip types (to education, social activities, shopping, etc.), not just trips to campus. Overall, there is limited research in terms of how a combination of transport and time-use factors can impact the on-campus participation of postsecondary students specifically, and further, how limitations in mobility and transport accessibility can potentially hinder scholastic achievement. 


\section{Data and Study Area}

2 Primary data for this project is drawn from a survey conducted in Fall 2015, which questioned students enrolled at seven university campuses in the Greater Toronto Area (GTA) about their travel behaviour (StudentMoveTO, 2015). The survey was conducted by sending mass emails to students prompting them to fill out a detailed online web form. The overall response rate was $8.3 \%$ across seven University campuses in the GTA. The survey was divided into two key components. The first includes a number of questions pertaining to students' stated living situation, demographics, student status, and travel behaviour as well as more qualitative responses on how students feel about transportation issues in the GTA and how transportation impacts their daily activities. The second part of the survey is a daily travel diary where students were asked to pinpoint on an interactive map where they travelled over the course of a day and input associated trip times, travel modes, activity purposes, and activity durations. The total number of respondents who commenced the survey was $n=15,226$, but the final sample size for our analysis was $n=2,011$ after removing respondents who did not participate in the travel diary portion of the survey, left blank responses for other relevant variables, and because of an error in the website that limited how many students were asked about their employment.

The study area, the GTA, is the largest metropolitan area in Canada and is home to the most postsecondary students of any Canadian region. In recent decades, the GTA has experienced significant increases in socioeconomic inequality and neighbourhood polarization (Hulchanski, 2010; Walks, 2013). These inequalities have been shown to align with transportation barriers, particularly for specific disadvantaged demographic groups like the elderly, low-income workers, and single-parent households (Roorda et al., 2010; Morency et al., 2011).

There are four University institutions spread across seven campuses; three centrally located in the urban core, and four located in suburban areas. Figure 1 is a map of campus locations in relation to major transport networks in the GTA. The three centrally located university campuses (Ryerson University, OCAD University, and the University of Toronto St. George) are well served by transit. Each are located within walking distance of at least one rapid transit line and numerous surface transit routes. They are also a short travel distance to Union Station, the terminal station for regional rail and bus lines. The four suburban campuses are less served by transit. Each has connections to surface local transit agencies and regional express buses, but at the time of the survey, they lacked any rapid transit and regional rail service connections. These campuses are unsurprisingly more car friendly. They have a cheaper and a greater supply of parking spaces, are surrounded by lane abundant arterial roads, and each are located near at least one major expressway. 
Figure 1: Map of campuses, transport networks, and the distribution of students in the Toronto area.

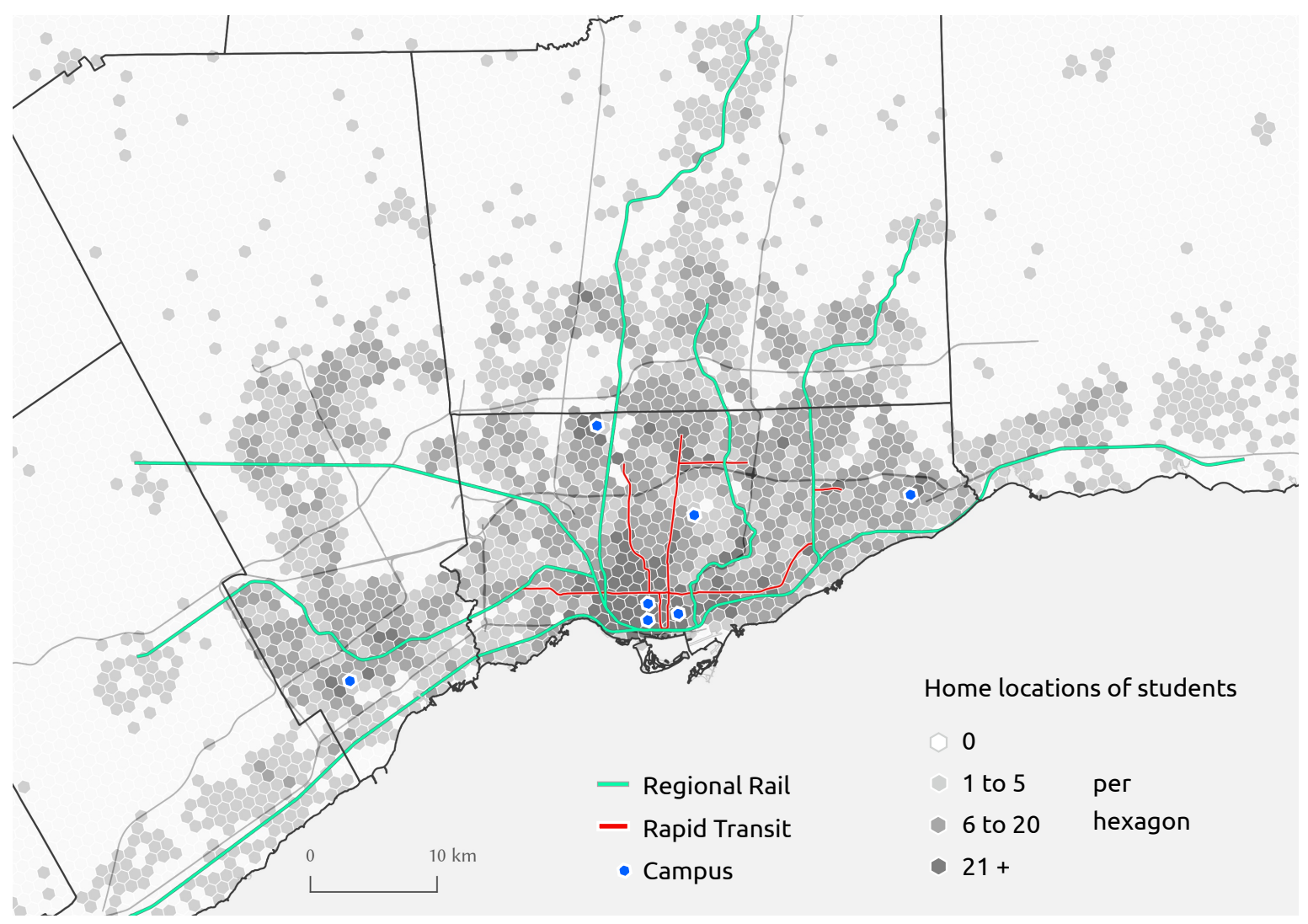

\section{Methods \& Analysis}

Our methodology is directed at answering how transportation and time-use factors prevent students from travelling to and participating in activities at their campuses in the GTA. This is divided into the following four steps.

- Descriptive analysis of survey responses.

- Derivation and descriptive analysis of transportation variables to examine the attributes of home-campus trips.

- Binomial logistic regression to examine the factors affecting whether students feel that their commutes are dissuading on-campus participation.

- Ordered logistic regression to examine how transport and time-use factors affect weekly school commute rates.

Description of the methods and the outputs of analysis for each of the aforementioned 
1 are described in more detail in the subsequent sub-sections.

\subsection{Descriptive Analysis of Survey Responses}

3 This section consists of a descriptive analysis of survey responses, with a focus on the questions relating to travel, participation, and time-use. Data is summarized in Table 1.

Of particular importance for this study were three yes/no questions that asked respondents about how their commutes impact on-campus participation. From these, $65 \%$ of respondents indicated that commutes dissuade them from coming to campus, $66 \%$ said their commutes limit them from participating in on-campus activities, and 46\% stated that they consider their commutes when selecting their courses. $35 \%$ of students answered yes to all three of these questions. Students also indicated how often they typically commute to campus peer week, with the average being 4.2 days per week. Chi-square tests between each of the three dichotomous variables and commute frequency were significant $(p<0.001)$, meaning that, unsurprisingly, students who feel that their commutes are a barrier to participation, commute to campus less frequently.

For responses regarding travel characteristics, the mode share for the sample of students across all seven campuses is $64 \%$ transit, $18 \%$ walking, $12 \%$ driving, and $6 \%$ biking. For comparison, mode share for regular work commutes in the GTA is $68 \%$ driving, 24\% transit, and only $7 \%$ for walking and biking combined (Statistics Canada, 2016). The majority of students cannot afford private vehicles and rely on public transit if they live too far from campus to walk or bike. The mode share for driving is however higher the suburban campuses $(20 \%)$, and lower in the three downtown campuses (only 4\%). Students attending the downtown campuses relied more on transit or utilized active modes.

The travel diary portion of the survey indicates the activities students' participated in over the course of a single day, and the durations of each activity, rounded to the nearest five minutes. These activities were subsequently coded into six categories: at home, at school, at work, shopping and services, social activities, and travel. Variables were then derived for how long students spend in each of these activity categories, the total number of trips made during the day, and the total time spent travelling between activities. Students on average spend 15 hours a day at home, and the remaining 9 hours doing activities outside of their homes. The average number of trips per day was 3.1 and $9 \%$ of students made more than 5 trips. On average, a student spends two hours travelling per day. The average length of a work shift for a university student was 6 hours, and if a student visits campus, they spend on average 5.75 hours there. 
Table 1: Survey Summary Statistics

\begin{tabular}{|c|c|c|c|}
\hline Variable & Amount & Variable & Amount \\
\hline Commute Frequency & & Student Status & \\
\hline$<3$ days per week & $11.3 \%$ & Undergraduate Full-Time & $71.2 \%$ \\
\hline 3 days per week & $15.8 \%$ & Undergraduate Part-Time & $4.9 \%$ \\
\hline 4 days per week & $27.1 \%$ & Graduate Full-Time & $21.1 \%$ \\
\hline 5 days per week & $33.0 \%$ & Graduate Part-Time & $2.8 \%$ \\
\hline$>5$ days per week & $12.8 \%$ & Campus & \\
\hline Gender & & UofT St.Geroge & $43.1 \%$ \\
\hline Female & $67.5 \%$ & UofT Mississauga & $5.5 \%$ \\
\hline Male & $32.5 \%$ & UofT Scarborough & $7.7 \%$ \\
\hline Average Age & 23.3 & York Glendon & $2.4 \%$ \\
\hline Typical Commute Mode & & York Keele & $28.0 \%$ \\
\hline Walk & $18.0 \%$ & OCAD University & $2.5 \%$ \\
\hline Bike & $6.4 \%$ & Ryerson University & $10.8 \%$ \\
\hline Transit & $64.0 \%$ & Household Type & \\
\hline Car as Passenger & $3.6 \%$ & Family & $60.3 \%$ \\
\hline Car as Driver & $7.9 \%$ & Roommates & $24.4 \%$ \\
\hline Transit Pass Owner & $43.9 \%$ & Partner & $14.1 \%$ \\
\hline Employment & & Alone & $1.2 \%$ \\
\hline Does Not Work & $42.4 \%$ & Has Dependent Children & \\
\hline 0-20 hours per week & $42.3 \%$ & None & $84.2 \%$ \\
\hline $20+$ hours per week & $15.3 \%$ & One & $6.9 \%$ \\
\hline Average Household Size & 3.6 & Two or More & $8.9 \%$ \\
\hline
\end{tabular}

\subsection{Network Analysis of Home-Campus Trips}

2 To examine the characteristics of student commutes, variables pertaining to homecampus trips were computed for every student in the survey who recorded a home location in the region. These were computed for descriptive purposes as well as for inputs to subsequent multivariate models. These variables were computed on custom-built multi-modal networks of the GTA which can be routed on for different travel modes. The networks were built using the open-source routing engines OpenTripPlanner and OSRM. The input data for the walking, biking, and driving edges were the topological edges and nodes from OpenStreetMap. Transit schedules were incorporated into these networks via GTFS data for nine transit agencies in the region. Using these networks, we computed travel times to campuses for different modes. In the survey, students recorded their home coordinates and which campus they attend, but did not indicate accurate travel times for their home-campus trips. To further analyze the attributes of student commutes, transit level-of-service factors were computed, including walking distances to transit stops, dwell times, and num- 
ber of transfers per transit trip. Because of variations in transit schedules, transit variables were computed for every minute in an hour, and then averaged over the onehour period. These variables were based on the home-campus trip with the shortest duration. The process of returning trip attributes, beyond just durations, was computationally intensive, so analysis was limited to just a single hour. The hour period of 9:00am to 10:00am was selected because it was the time in which students make the most home-campus trips.

From this analysis, the average one-way commute for university students based on their recorded typical travel mode was 48 minutes and the median commute time was 40 minutes. This is substantially more than the overall, non-student specific population. The average one-way travel time for a typical work commute in the GTA is 34 minutes (Statistics Canada, 2016). Students who live closer to campus, were more likely to travel by walking or cycling. The average travel time by cyclists was 17 minutes, and for students who walk to campus, 23 minutes. For students who commute by transit, the average one-way commute time was 61 minutes and $20 \%$ of transit riders have commutes in excess of 90 minutes. While each campus is served by several local and regional transit routes, most students do not live along these lines and have to transfer between vehicles. $87 \%$ of transit riders have to typically transfer at least once, and $46 \%$ have to transfer two or more times. The average waiting time for a student commuting by transit is 10 minutes, which accounts for $16 \%$ of the overall trip time. The average transit trip also includes walking 1.3 kilometres (combined for both ends of a trip).

\subsection{Modelling if Commutes Dissuade Participation}

\section{4} $\epsilon_{i}$.

The aforementioned survey and network derived variables were used as input into multivariate regression models to examine what affects whether students feel that their commutes do or do not dissuade them from participating on-campus. Binomial logistic regression was used to model the determinants for three dichotomous variables, the answers to these survey questions:

- $\left(Y_{1}\right)$ Does your commute sometimes discourage you from coming to campus?

- $\left(Y_{2}\right)$ Do you pick your courses based on your commute?

- $\left(Y_{3}\right)$ Does your commute discourage you from participating in university-organized activities or events?

Logistic regression is often used to model categorical outcome variables, like the probability of whether a student responds 'yes' or 'no' to the questions above. Logistic regression examines the outputs in terms of the probability, $P_{i}$, of experiencing an event as a function of a vector of independent variables, $X_{i}$, and random components 


$$
P_{i}=\frac{1}{1+e^{-\left(\beta X_{i}+\epsilon_{i}\right)}}
$$

Initial selection of variables into the models were determined via bi-variate statistical tests. Chi-square tests were used to compare the dichotomous dependents with categorical data (e.g. travel mode) and one-way analysis of variance tests for comparing with numerical data (e.g. travel time). Estimation of the model was computed via iteration to find the coefficients that achieve maximum log likelihood (Pampel, 2000). Non-significant variables were not included in the final models. The goodness of fit of the resulting model is evaluated with the following statistic as per Ben-Akiva and Lerman (1985).

$$
\rho^{2}=1-\frac{L(\beta)}{L(c)}
$$

Where $L(\beta)$ is the maximum log-likelihood for the entire model and $L(c)$ is the maximum log-likelihood for the model which only contains the intercept, the least informative model. The greater $\rho^{2}$, the better the goodness of fit. Furthermore, the $\bar{\rho}^{2}$ statistic is computed to control between models with different quantities of coefficients $k$.

$$
\bar{\rho}^{2}=1-\frac{L(\beta)-k}{L(c)}
$$

Regression outputs for each of the three dichotomous dependent variables are displayed in Table 2. The results are provided as odds ratios. From the regression outputs, the duration of a home-campus trip for a student's typical travel mode has a significant effect on whether commutes dissuade participation. The greater the duration of a commute, the more likely a student is to say that their commute dissuades on-campus participation. Looking at travel mode, students who rely on public transit were more likely to state that their commutes dissuade participation, even after controlling for home-campus travel time. The more students transfer between vehicles, the more likely they are to state that their commutes dissuade them from coming to campus, even after controlling for travel time. This variable was not significant for whether students' commutes dissuade participation in on-campus activities or if they pick courses based on their commutes. Other transit level-of-service variables, like walking distance and initial wait times, were also not found to be significant. 
Table 2: Binary Logistic Models of Barriers to Participation

\begin{tabular}{|c|c|c|c|c|c|c|}
\hline & $Y_{1}$ & & $Y_{2}$ & & $Y_{3}$ & \\
\hline $\bar{n}$ & 2011 & & 2011 & & 2011 & \\
\hline$L(\beta)$ & -1100 & & -1175 & & -979 & \\
\hline$\rho^{2}$ & 0.152 & & 0.152 & & 0.243 & \\
\hline \multirow[t]{2}{*}{$\bar{\rho}^{2}$} & 0.140 & & 0.139 & & 0.238 & \\
\hline & OR & $p$ & OR & $p$ & OR & $p$ \\
\hline Intercept & 0.869 & 0.816 & 0.328 & 0.000 & 0.386 & 0.000 \\
\hline \multicolumn{7}{|l|}{ Gender } \\
\hline Female & reference & & reference & & reference & \\
\hline Male & 0.813 & 0.063 & 0.607 & 0.000 & 0.734 & 0.009 \\
\hline Age & 0.963 & 0.000 & 0.976 & 0.008 & 0.979 & 0.416 \\
\hline \multicolumn{7}{|l|}{ Student Status } \\
\hline Undergrad Full-Time & - & - & reference & & - & - \\
\hline Undergrad Part-Time & - & - & 0.873 & 0.584 & - & - \\
\hline Graduate Full-Time & - & - & 0.571 & 0.000 & - & - \\
\hline Graduate Part-Time & - & - & 0.829 & 0.579 & - & - \\
\hline \multicolumn{7}{|l|}{ Campus } \\
\hline UofT St George & reference & & reference & & - & - \\
\hline UofT Mississauga & 0.584 & 0.021 & 1.011 & 0.963 & - & - \\
\hline UofT Scarborough & 1.318 & 0.206 & 1.585 & 0.012 & - & - \\
\hline York Glendon & 0.411 & 0.010 & 1.728 & 0.098 & - & - \\
\hline York Keele & 1.133 & 0.364 & 2.012 & 0.000 & - & - \\
\hline OCAD University & 0.848 & 0.626 & 1.928 & 0.044 & - & - \\
\hline Ryerson University & 1.107 & 0.600 & 1.548 & 0.012 & - & - \\
\hline \multicolumn{7}{|l|}{ Typical Commute Mode } \\
\hline Walk & reference & & reference & & reference & \\
\hline Bike & 0.912 & 0.704 & 0.577 & 0.068 & 0.723 & 0.177 \\
\hline Transit & 1.617 & 0.042 & 1.556 & 0.013 & 2.765 & 0.000 \\
\hline Car as Passenger & 0.851 & 0.597 & 1.036 & 0.907 & 0.865 & 0.638 \\
\hline Car as Driver & 1.143 & 0.616 & 0.910 & 0.719 & 0.967 & 0.903 \\
\hline Home-campus trip time & 1.017 & 0.000 & 1.017 & 0.000 & 1.033 & 0.000 \\
\hline Number of Transfers & 1.302 & 0.035 & - & - & - & - \\
\hline \multicolumn{7}{|l|}{ Employment } \\
\hline Does Not Work & reference & & reference & & - & - \\
\hline 0-20 hours per week & 1.369 & 0.007 & 1.439 & 0.001 & - & - \\
\hline $20+$ hours per week & 1.236 & 0.195 & 1.711 & 0.001 & - & - \\
\hline
\end{tabular}

$\mathbf{Y}_{\mathbf{1}}=$ Does your commute sometimes discourage you from coming to campus?

$\mathbf{Y}_{\mathbf{2}}=$ Do you pick your courses based on your commute?

$\mathbf{Y}_{\mathbf{3}}=$ Does your commute discourage you from participating in university-organized activities or events? 
Employment, in terms of hours per week, had a negative effect on students feeling that commutes dissuaded participation. Compared to not working, working less than 20 hours per week was associated with a 37\% increase in students stating that their commute discourages travelling to campus. At the same time, working was associated with a $44 \%$ (0-20 hours of work) and $71 \%$ (working more than 20 hours per week) increase in students selecting their courses based on their commutes. Employment was not a significant factor for whether students participated in extra-curricular activities on campus. The models were also tested for interaction terms between employment and travel time, but this did not provide significant improvement on model fit.

Surprisingly, household level factors like living situation (e.g. family, roommates, alone), number of dependent children, household size, or age of other household members were not significant or they were already captured by other variables. As well, time-use factors like average number of trips made per day, time spent shopping, or time spent visiting friends or family were not significant. Both age and gender were significant however, females were more likely to have their commutes deter them from participating than males, and younger students were more likely to respond negatively towards commuting compared to older students. There was also some significant variation between campuses. Two of the suburban campuses, U of T Mississauga and York's Glendon campus, were less likely to state that commutes dissuaded them from travelling to campus. While students at the two other suburban campuses, U of T Scarborough and York's larger Keele campus, were more likely to state that they pick courses based on their commute.

\subsection{Modelling Weekly Commute Rates}

Multivariate ordered logistic regression was used to model how many days a student visits campus per week. This tests the hypothesis of whether students who have longer commutes, and have other time commitments like employment, are less likely to attend campus on a per week basis.

Traditionally, trip rates have been modelled at a zonal scale via linear regression. In the case of individual weekly commute rates, the number of trips per week is a limited dependent variable; it has to be an integer from 0 to 7 . An ordinary linear model would not abide to these restrictions. There would also most likely be issues with variance normality if a linear model is applied to this variable. Moreover, the difference between making 3 trips and 4 trips might be more significant than a difference between 4 and 5 trips. Ordinal data models, like ordered logit and ordered probit regression, have been applied to model individual trip rates, and in particular for vulnerable populations like low income or the elderly (Schmöcker et al., 2005; Paez et al., 2007; Roorda et al., 2010). Following this precedent in the literature, we use an ordered logistic regression to model weekly commute frequency. In ordered 
logistic regression, the probability of someone making $Y_{C}$ trips per week is modelled via utility function, $U$. Since there were few occurrences in the data of students commuting 0,1 , or 2 days per week, or 6 or 7 days per week, these were combined into single categories of less than 3 days per week and more than 5 days per week, respectively.

$$
Y_{C} \begin{cases}<3, & \text { if } U_{i}<\lambda_{1} \\ =3, & \text { if } \lambda_{1}<U_{i}<\lambda_{2} \\ =4, & \text { if } \lambda_{2}<U_{i}<\lambda_{3} \\ =5, & \text { if } \lambda_{3}<U_{i}<\lambda_{4} \\ >5, & \text { if } U_{i}>\lambda_{4}\end{cases}
$$

The utility, $U$, is unobservable, but it can modelled linearly via its systematic and random components.

$$
U_{i}=\beta X_{i}+\epsilon_{i}
$$

The thresholds, $\lambda$, and the coefficients, $\beta$, were estimated via maximum likelihood. Initial selection of variables into the model were determined via bi-variate statistical tests. Only significant variables are included in the final model. Goodness of fit was analyzed with the same $\rho^{2}$ and $\bar{\rho}^{2}$ statistics as before (Ben-Akiva \& Lerman, 1985).

Coefficients of the output model and their corresponding $p$-values pertaining to their statistical significance are displayed in Table 3. This table also includes the marginal effects on probability of each class membership. The goodness of fit statistics for this model, $\rho^{2}$ and $\bar{\rho}^{2}$, and the signs of variables are similar to other individual trip rate and tele-commute frequency models in the GTA (Roorda et al., 2010; Habib, 2017).

Overall, students who have longer commutes are less likely to attend campus compared to students with shorter commutes, even after controlling for sociodemographic factors, student status, and which campus they attend. If commute times are equal, students who travel by car, either as a solo driver or as a passenger, commute less often in reference to students who walk or bike to campus. Students who commute by transit also commute less in reference to those who walk. Students with a transit pass are more likely to attend campus more days per week. Transit level-of-service factors like wait times, walking distance, and number of transfers were not significant and thus not included in the final model. 
Table 3: Ordered logistic model of weekly commute rates

\begin{tabular}{ccccc}
\hline \multicolumn{2}{c}{ Model Summary } & & $\lambda$ & $p$ \\
\hline$n$ & 2011 & $\lambda_{1}$ & -6.175 & 0.000 \\
$L(\beta)$ & -2681 & $\lambda_{2}$ & -4.768 & 0.000 \\
$\rho^{2}$ & 0.123 & $\lambda_{3}$ & -3.273 & 0.000 \\
$\bar{\rho}^{2}$ & 0.116 & $\lambda_{4}$ & -1.173 & 0.000 \\
\hline
\end{tabular}

\begin{tabular}{|c|c|c|c|c|c|c|c|}
\hline \multirow[b]{2}{*}{ Variable } & \multirow[b]{2}{*}{$\beta$} & \multirow[b]{2}{*}{$p$} & \multicolumn{5}{|c|}{ Marginal Effects on Probabilities } \\
\hline & & & $P(<3)$ & $P(3)$ & $P(4)$ & $P(5)$ & $P(>5)$ \\
\hline \multicolumn{8}{|l|}{ Gender } \\
\hline Female & reference & & & & & & \\
\hline Male & 0.422 & 0.000 & -0.026 & -0.047 & -0.032 & 0.069 & 0.034 \\
\hline Age & -0.069 & 0.000 & 0.004 & 0.008 & 0.005 & -0.012 & -0.005 \\
\hline \multicolumn{8}{|l|}{ Student Status } \\
\hline Undergrad Full-Time & reference & & & & & & \\
\hline Undergrad Part-Time & -1.536 & 0.000 & 0.178 & 0.169 & -0.049 & -0.229 & -0.069 \\
\hline Graduate Full-Time & -0.381 & 0.002 & 0.027 & 0.045 & 0.019 & -0.065 & -0.027 \\
\hline Graduate Part-Time & -1.801 & 0.000 & 0.233 & 0.179 & -0.088 & -0.253 & -0.072 \\
\hline \multicolumn{8}{|l|}{ Campus } \\
\hline UofT St. George & reference & & & & & & \\
\hline UofT Mississauga & -0.453 & 0.020 & 0.035 & 0.055 & 0.017 & -0.077 & -0.029 \\
\hline UofT Scarborough & -1.158 & 0.000 & 0.114 & 0.138 & -0.007 & -0.185 & -0.060 \\
\hline York Glendon & -0.896 & 0.001 & 0.083 & 0.109 & 0.003 & -0.146 & -0.048 \\
\hline York Keele & -0.994 & 0.000 & 0.078 & 0.117 & 0.033 & -0.164 & -0.065 \\
\hline OCAD University & -0.703 & 0.009 & 0.060 & 0.086 & 0.012 & -0.117 & -0.041 \\
\hline Ryerson University & -0.267 & 0.070 & 0.019 & 0.031 & 0.014 & -0.045 & -0.019 \\
\hline \multicolumn{8}{|l|}{ Typical Commute Mode } \\
\hline Walk & reference & & & & & & \\
\hline Bike & 0.122 & 0.548 & -0.007 & -0.014 & -0.009 & 0.020 & 0.010 \\
\hline Transit & -0.634 & 0.000 & 0.038 & 0.070 & 0.048 & -0.103 & -0.053 \\
\hline Car as Passenger & -0.618 & 0.019 & 0.051 & 0.075 & 0.015 & -0.104 & -0.037 \\
\hline Car as Driver & -0.623 & 0.005 & 0.050 & 0.075 & 0.017 & -0.105 & -0.038 \\
\hline Home-Campus Travel Time & -0.013 & 0.000 & 0.001 & 0.002 & 0.001 & -0.002 & -0.001 \\
\hline Has a Transit Pass & 0.468 & 0.000 & -0.029 & -0.052 & -0.033 & 0.077 & 0.037 \\
\hline \multicolumn{8}{|l|}{ Employment } \\
\hline Does Not Work & reference & & & & & & \\
\hline 0-20 hours per week & -0.264 & 0.004 & 0.017 & 0.030 & 0.017 & -0.044 & -0.020 \\
\hline $20+$ hours per week & -0.776 & 0.000 & 0.063 & 0.093 & 0.021 & -0.130 & -0.048 \\
\hline Number of Trips per Day & -0.050 & 0.061 & 0.003 & 0.006 & 0.003 & -0.008 & -0.004 \\
\hline
\end{tabular}


Males were found to have a greater likelihood of commuting to campus than females. Younger students commute to campus more often than older students, even after controlling for student status. In reference to the largest campus, $\mathrm{U}$ of $\mathrm{T}$ St. George, students are likely to commute less frequently to both York University's campuses, U of T Scarborough, and OCAD University. Household factors like living situation (e.g. family, roommates, etc.), number of dependent children, or household size were not found to be significant.

Employment, in terms of number of hours per week, has a negative effect on how often students visit campus per week. The more one works, the less likely they are to attend campus. Time spent in other activities like shopping or visiting friends was not significant. The total number of trips a student makes per day was, however, significant. Students who recorded more trips during a day commute to campus less often. This is a summation of all trips (work, school, shopping, socializing), so students with busier lives, those who partake in more activities during the day, attend campus less often on a weekly basis.

\section{Discussion \& Recommendations}

The regression outputs indicate that students with longer commute durations are less likely to travel to campus and participate in on-campus activities. This is similar to other research on postsecondary travel where students who live further from destinations (education and otherwise), have lower daily trip rates (Kamruzzaman et al., 2011; Wang et al., 2012). Model results also show that students with longer travel times are also more likely to select courses based on their commute. Since educational retention literature has shown that less on-campus participation results in less opportunity for scholastic success (Tinto, 1999; Bozick, 2007), the inequalities of transport accessibility and mobility can thus also potentially hinder students to succeed at their educational pursuits. In other words, some students have a much greater barrier to access educational resources than others because of where students live in reference to their campus and connecting transport networks. This also aligns with other research in the GTA, that subgroups living in less accessible areas of the region have lower trip rates (Roorda et al., 2010).

A potential appeasement strategy to transportation being a barrier to on-campus participation is to increase online course offerings and improve digital educational resources for students who study from home. While this would reduce some detriments of not visiting campus, it does not account for the in-person social interactions, inclass learning experiences, and participation in other on-campus activities that are correlated with academic success (Tinto, 1999; Bozick, 2007). Another strategy would be to decrease the costs of on-campus housing. Many prospective students cannot afford living on or near campus alongside high tuition fees (over $60 \%$ in our sample 
live with family). Decreasing the costs of housing for students near campuses could 2 be a strategy enacted by universities to encourage some students to live closer and therefore limit transportation barriers.

Another important finding in our analysis is that the more time students spend working, the less often they attend campus, and the more likely they feel that their commutes dissuade them from participating in on-campus activities. This aligns with the zero-sum perspective in the literature that educational participation is impacted by part-time employment (Bozick, 2007; Dwyer et al., 2013). However, household level factors, like whether university students have dependent children or recorded that they spend more time shopping, were insignificant in whether they travelled to campus more often per week or if commutes dissuaded on-campus participation. This is contrary to some literature (Reay et al., 2002), which states that these household factors should deter travelling to campus. The total number of trips a student makes per day, however, was negatively related to days per week commuting to campus. This suggests that students with busier lives, those who do more activities during a day, attend campus less often on a weekly basis.

The monetary costs of travelling are also a potential barrier. Commute frequency was shown to be greater for active modes like walking or biking. These have minimal costs compared to driving (e.g. car upkeep, insurance, parking) or transit (e.g. trip fares or monthly passes). There are several transit agencies in the GTA, each with their own fare structure. Students who have to transfer between the transit agencies have compounded costs. From the weekly commute rate model, those students with transit passes commute to campus more days per week. Once students pay the upfront cost of a transit pass, they are more likely to travel more often to justify their expense and maximize their return on investment. At the time of writing, transit passes are only marginally discounted for University students in the GTA. Transit passes and individual fares should be discounted further for University students, to reduce the financial barrier of travelling to campus, particularly for students who rely on more than one transit agency.

Another finding was that the fewer number of transfers on a journey reduced the probability of a student responding that commutes dissuade participation. Yet $87 \%$ of students who commute by transit need to transfer at least once between vehicles, and $46 \%$ have to transfer two or more times. Future planning of transit service to campuses should aim to reduce the number of transfers required by students. This could follow literature on providing transit service for postsecondary students living in less accessible areas (Kamruzzaman et al., 2011). As well, the scheduling of courses and transit timetables could be designed for more harmonious concordance, particularly in suburban campuses which are served by less frequent bus service. For example, transit schedules could be tweaked to arrive shortly before classes begin and leave shortly after classes end. This also highlights the importance of a follow up survey. If there are changes in transit services to campuses, a follow up survey would 
1 facilitate analysis to examine to what extent on-campus participation will change 2 due to accessibility improvements that new transit service would provide, and also 3 facilitate difference-in-difference comparisons with campuses that did not have any changes in transit service.

Other transit level-of-service factors like waiting times for transit vehicles, either when first arriving at a transit stop, or during a transfer were not found to be significant. Only overall travel time matters. This finding could potentially be due to students making use of real-time applications so they don't have to wait as long since they can time their arrivals to transit stops more efficiently. Walking distance to transit stops was also found not to deter commuting to campus, after controlling for overall trip time. Students, many being young and able bodied, were not dissuaded by the active portions of a trip. Furthermore, students who commute by bike or by walking were least deterred to participate by their commutes, even after controlling for travel time. This aligns with Páez and Whalen (2010) who found that students who travel by car or transit are more dissatisfied with their commutes than those who walk or cycle. In our study, walking accounted for $18 \%$ of commutes, and cycling only $6 \%$. Yet $35.5 \%$ of those surveyed who travel by transit, would actually have a faster commute if they cycled. Encouraging cycling to campus should therefore be a priority. This could include designing safer bike infrastructure near campus and student discounts for bike-share or other bike rental services. Not only would this potentially improve on-campus participation, but it would also have other benefits like reducing crowding on public transit, decreasing the monetary costs of travel for students, and be beneficial for students' health.

The main limitation of our study is that it does not directly link with student outcomes. Previous literature has shown that on-campus participation is correlated with success in education (Tinto, 1999; Bozick, 2007). Our study provides analysis of how time-use and transportation factors can limit on-campus participation and selecting courses. But future student travel surveys should be designed to better directly link between time-use and transportation with student outcomes, like grades and retention rates, not just on-campus participation. Accuracy of future surveys could also be improved through multiple day activity diaries, rather than just a single day, and using GPS traces to examine trip attributes, rather than inferring trip attributes from transport network graphs.

Another potential criticism of our work is the issue of endogeneity in the trip rate model due to a potential causality loop between the time use independent variables (e.g. employment) and the dependent variable, weekly commute rate. Maybe students study less, and then partake in more employment because they have more time available. Maybe students do not want to take as many classes, so they do not mind living farther away. This is partly controlled for in the model in whether a student is full-time or part-time, but there were no specific variables in the survey for how many classes or in-class hours a student is enrolled in. From the first set 
of models, students who are employed are more likely to state that commuting gets in the way of participation compared to students who do not work. The combined analysis of these outcomes thus strengthen the conclusions about how commutes and employment dissuade participation. Nevertheless, future postsecondary student surveys should provide more detailed questions on student's enrolment (e.g. in-class 3 hours) to compare with their participation.

\section{Conclusion}

8 In summary, this paper examined how transportation and time-use factors prevent 9 students from attending their campuses in a large metropolitan area. This work was 10 based on data from a recent 1-day travel survey of students across seven university 11 campuses in the GTA alongside a set of computationally derived transport accessi12 bility and transit level-of-service factors. Multivariate logistic regression models were 13 employed to uncover the mobility-related determinants of on-campus participation. 14 Results showed that students participate less often if they have longer commute times 15 to campus or if they partake in employment. And since previous literature has found 16 that on-campus participation is linked with student success (Tinto, 1993, 1999; Boz17 ick, 2007), policy should then be directed a these transportation barriers, with focus 18 on better scheduling of transit service to campuses to be in concordance with stu19 dent schedules, more affordable transit fares, encouraging active modes of transport, 20 and decreasing the costs of on-campus housing. Doing so would reduce transport 21 related accessibility inequalities and provide more equal opportunity for students to

22 participate and succeed in postsecondary education. 


\section{References}

2 Abercrombie, N. (1974). The university in an urban environment: a study of 3 activity patterns from a planning viewpoint (Vol. 2). Sage Publications (CA). 4 Ben-Akiva, M. E., \& Lerman, S. R. (1985). Discrete choice analysis: theory and application to travel demand (Vol. 9). MIT press.

Bozick, R. (2007). Making it through the first year of college: The role of students' economic resources, employment, and living arrangements. Sociology of education, 80(3), 261-285.

Cullen, I., \& Godson, V. (1975). Urban networks: the structure of activity patterns. Progress in planning, 4, 1-96.

Delmelle, E. M., \& Delmelle, E. C. (2012). Exploring spatio-temporal commuting patterns in a university environment. Transport Policy, 21, 1-9.

Dwyer, R. E., Hodson, R., \& McCloud, L. (2013). Gender, debt, and dropping out of college. Gender 83 Society, 27(1), 30-55.

Farber, S., \& Fu, L. (2017). Dynamic public transit accessibility using travel time cubes: Comparing the effects of infrastructure (dis) investments over time. Computers, Environment and Urban Systems, 62, 30-40.

Frenette, M. (2004). Access to college and university: Does distance to school matter? Canadian Public Policy/Analyse de Politiques, 427-443.

Frenette, M. (2006). Too far to go on? distance to school and university participation. Education Economics, 14 (1), 31-58.

Grengs, J. (2015). Nonwork accessibility as a social equity indicator. International Journal of Sustainable Transportation, 9(1), 1-14.

Habib, K. N. (2017). On the factors influencing the choices of weekly telecommuting frequencies of post-secondary students in toronto. In Transportation research board 96th annual meeting, transportation research board.

Hägerstraand, T. (1970). What about people in regional science? Papers in regional science, $24(1), 7-24$.

Hanson, S. (1982). The determinants of daily travel-activity patterns: relative location and sociodemographic factors. Urban Geography, 3(3), 179-202.

Hulchanski, J. D. (2010). The three cities within toronto. Cities Centre, University of Toronto.

Kamruzzaman, M., Hine, J., Gunay, B., \& Blair, N. (2011). Using gis to visualise and evaluate student travel behaviour. Journal of Transport Geography, 19(1), 13-32.

Kittelson \& Associates. (2003). Transit capacity and quality of service manual (No. 100). Transportation Research Board. Federal Transit Administration and Transit Cooperative Research Program and Transit Development Corporation.

Lei, T. L., \& Church, R. L. (2010). Mapping transit-based access: integrating gis, routes and schedules. International Journal of Geographical Information 
Science, 24(2), 283-304.

Lucas, K. (2012). Transport and social exclusion: Where are we now? Transport policy, 20, 105-113.

Lundberg, B., \& Weber, J. (2014). Non-motorized transport and university populations: an analysis of connectivity and network perceptions. Journal of Transport Geography, 39, 165-178.

Lynch, K. (1981). A theory of good city form. MIT Press.

Martens, K. (2016). Transport justice: Designing fair transportation systems. Routledge.

McCray, T., \& Brais, N. (2007). Exploring the role of transportation in fostering social exclusion: The use of gis to support qualitative data. Networks and Spatial Economics, 7(4), 397-412.

Miller, H. J. (1991). Modelling accessibility using space-time prism concepts within geographical information systems. International Journal of Geographical Information System, 5(3), 287-301.

Miller, H. J. (1999). Potential contributions of spatial analysis to geographic information systems for transportation (gis-t). Geographical Analysis, 31(4), 373-399.

Moniruzzaman, M., \& Farber, S. (2017). What drives sustainable student travel? mode choice determinants in the greater toronto area. International Journal of Sustainable Transportation, 1-13.

Morency, C., Paez, A., Roorda, M. J., Mercado, R., \& Farber, S. (2011). Distance traveled in three canadian cities: Spatial analysis from the perspective of vulnerable population segments. Journal of Transport Geography, 19(1), 39-50.

Owen, A., \& Levinson, D. M. (2015). Modeling the commute mode share of transit using continuous accessibility to jobs. Transportation Research Part A: Policy and Practice, 74, 110-122.

Paez, A., Scott, D., Potoglou, D., Kanaroglou, P., \& Newbold, K. B. (2007). Elderly mobility: demographic and spatial analysis of trip making in the hamilton cma, canada. Urban Studies, 44(1), 123-146.

Páez, A., \& Whalen, K. (2010). Enjoyment of commute: a comparison of different transportation modes. Transportation Research Part A: Policy and Practice, $44(7), 537-549$.

Pampel, F. C. (2000). Logistic regression: A primer (Vol. 132). Sage Publications.

Reay, D., Ball, S., \& David, M. (2002). It's taking me a long time but i'll get there in the end: mature students on access courses and higher education choice. British Educational Research Journal, 28(1), 5-19.

Roorda, M. J., Páez, A., Morency, C., Mercado, R., \& Farber, S. (2010). Trip generation of vulnerable populations in three canadian cities: a spatial ordered probit approach. Transportation, 37(3), 525-548.

Schmöcker, J.-D., Quddus, M., Noland, R., \& Bell, M. (2005). Estimating trip 
1 generation of elderly and disabled people: analysis of london data.

2 Transportation Research Record: Journal of the Transportation Research

3 Board(1924), 9-18.

Shannon, T., Giles-Corti, B., Pikora, T., Bulsara, M., Shilton, T., \& Bull, F. (2006). Active commuting in a university setting: assessing commuting habits and potential for modal change. Transport Policy, 13(3), 240-253.

Statistics Canada. (2016). 2016 Census of Population.

StudentMoveTO. (2015). About studentmoveto. Retrieved from

9 http://www.studentmoveto.ca/about/

10 Tinto, V. (1993). Leaving college : rethinking the causes and cures of student 11 attrition. University of Chicago Press.

12 Tinto, V. (1999). Taking retention seriously: Rethinking the first year of college. 13 NACADA journal, 19(2), 5-9.

14 Walks, A. (2013). Income inequality and polarization in canadas cities: An examination and new form of measurement. Cities Centre, University of Toronto, 227.

Wang, X., Khattak, A., \& Son, S. (2012). What can be learned from analyzing university student travel demand? Transportation Research Record: Journal of the Transportation Research Board(2322), 129-137. 